\title{
XXXVI. On the constitution of bebeerine
}

\section{Douglas Maclagan M.D. F.R.S.E. \& Thomas G. Tilley Esq.}

To cite this article: Douglas Maclagan M.D. F.R.S.E. \& Thomas G. Tilley Esq. (1845) XXXVI. On the constitution of bebeerine, Philosophical Magazine Series 3, 27:180, 253-257, DOI: 10.1080/14786444508645271

To link to this article: http://dx.doi.org/10.1080/14786444508645271

曲 Published online: 30 Apr 2009.

Submit your article to this journal

Џ Article views: 2

Q View related articles $\sqsubset$ 
XXXVI. On the Constitution of Bebeerine. By Dovglas Maclagan, M.D., F.R.S.E., and Thomas G. Tilley, Esq., Professor of Chemistry in the Queen's College, Birmingham*.

BEBEERINE is the name given by Dr. Rodie of Demerara to an organic base, of which he pointed out the existence, in the bark of a tree of that colony known by the names of Bebeeru or Green heart. 'This tree has recently been examined botanically by Sir Robert Schomburgk, and found to be a species of Nectandra, which in compliment to Dr. Rodie he has named N.Rodiei (Hooker's London Journal of Botany, December 1844).

The general properties of the alkali, and the preparation of its sulphate for medicinal use, were further described by one of us in a paper read before the Royal Society of Edinburgh in April 1843 (Transactions, vol. xv. part iii.). In this memoir an account was given of the preparation of bebeerine, in what was regarded as a state of chemical purity, and of its separation by means of æether from what was believed to be another alkaline matter, sipeerine; but as the substance is neither crystallizable nor colourless, it could not decidedly be affirmed to be chemically pure until its constitution had been determined by ultimate analysis. This desideratum it is proposed to supply in the present paper.

The chief difficulty in preparing the pure alkali arose from the truublesome process required to free it from adhering tannin, considerable loss being experienced in the methods then adopted. This has subsequently been accomplished with greater facility by the following process, which may be applicable to the purification of other organic bases.

The sulphate prepared for medicinal use, which is always more or less impure, is precipitated by ammonia; and the alkaline matter thus separated, is, after washing with water, triturated with about an equal weight of freshly precipitated and moist hydrated oxide of lead. The magma thus formed is then dried over the water-bath, and the alkali is taken up by absolute alcohol. On distilling off the spirit, the organic base is left in the form of a transparent orange-yellow resinous mass, as described in the paper above quoted. This, on being dried, pulverized, and treated with successive portions of pure æether, is in great part dissolved in this fluid. The dissolved portion, on distilling off the æther, is obtained in the form of a translucent, amorphous, but homogeneous resinous-looking substance, of a pale yellow colour, and possessed of all the pro-

* Communicated by the Authors. 
perties of an organic alkali. This is pure bebeerine, as described in April 1843.

Bebeerine thus obtained does not crystallize. It is very soluble in alcohol, less so in æther, and very sparingly in water. Heated, it fuses; and the heat being continued it swells up, giving off vapours of a strong peculiar odour, and burns without residue. Subjected to the action of oxidizing agents, it gives with bichromate of potash and sulphuric acid a black, and with nitric acid a yellow resin. It forms with acids salts which are all uncrystallizable; with perchloride of gold, mercury, copper, iron and platinum, it gives precipitates which are soluble to a certain extent in hot water and alcohol, but which on the solution cooling are not deposited from it in a crystalline form*.

To ascertain the composition of the base, two portions of it, prepared at separate times, were subjected to combustion.

(1.) 0.300 grms. substance gave 0.179 water and 0.788 carbonic acid.

(2.) 0.3505 substance gave 0.1965 water and 0.922 carbonic acid. acid.

(3.) 0.350 substance gave 0.2095 water and 0.914 carbonic

Nitrogen was estimated by Will.and Varrentrapp's method.

(1.) 0.4030 substance gave 0.3490 ammonio-chloride of platinum.

(2.) 0.417 substance gave 0.1175 platinum.

These numbers lead to the following per-centage proportions, the atomic weight of carbon being taken at 75.85 .

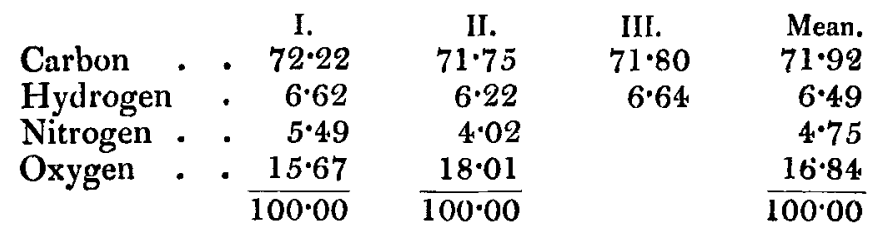

The combination with chloride of platinum was made use of to determine the atomic weight of the base.

(1.) 0.6380 salt gave 0.1215 platinum $=19.04$ per cent.

* When precipitated by ammonia from its solutoin in acids, it is obtained in the form of a very pale yellow powder. This was examined with a view to determine whether or not it was a hydrate of the alkali. It was washed, dried in vacuo over sulphuric acid, and heated in an oil-bath. At $308^{\circ} \mathrm{Fahr}$, it began to soften, and at $370^{\circ}$ it fused into a transparent brown resinous mass. It dit not sensibly lose weight during the process, and had undergone no change in properties from exposure to this temperature, as it retained its perfect solubility in acids, and formed with them the usual bright yellow solution. 
(2.) 0.6250 salt gave 0.1200 platinum $=19.28$ per cent. (3.) 0.5335 gave 0.1080 platinum $=20.20$ per cent. The platinum salt was burned with chromate of lead. 0.4005 salt gave 0.152 water and 0.6232 carbonic acid.

For nitrogen.- $0 \cdot 430$ salt gave 0.177 ammonio-chloride of platinum.

Chlorine was estimated by heating with lime, dissolving in nitric acid, and precipitating by nitrate of silver.

0.420 salt gave 0.3730 chloride of silver.

These numbers lead to the following formulæ:-

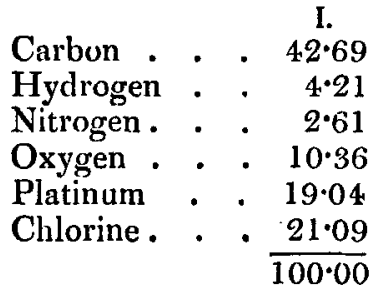

II.

III.

$19 \cdot 24$

$20 \cdot 24$

I. II. III. Atoms.

Carbon . $4 \cdot 2 \cdot 69$

I1.

$$
35=
$$

Hydrogen $4: 21$

Nitrogen . 2.61

Oxygen $\cdot 10.36$

Platinum $19 \cdot 04$

Chlorine $\frac{.21 \cdot 09}{100 \cdot 00}$

$\begin{array}{rrr}35 & =2654 \cdot 76 & 42 \cdot 43 \\ 42 & 262.07 & 4 \cdot 18 \\ 2 & 177 \cdot 04 & 2 \cdot 83 \\ 6 & 600 \cdot 00 & 9 \cdot 59 \\ 1 & 1233.30 & 19 \cdot 73 \\ 6 & \frac{1328 \cdot 00}{6255 \cdot 17} & \frac{21.23}{99.99}\end{array}$

The atomic weight calculated from the quantity of platinum found, is-

I. $6476 \cdot 0$

II. $64,23 \cdot 4$

III. $6092 \cdot 2$

$$
\frac{6092 \cdot 2}{3}=6330 \cdot 2\left\{\begin{array}{l}
\text { mean found atomic weight of pla- } \\
\text { tinum salt. }
\end{array}\right.
$$

Referring to our previous numbers, we find-

Atoms.

Carbon $\quad .35=2654 \cdot 75$

Hydrogen $\quad 40 \quad 249.59$

Nitrogen . $2 \quad 177.04$

Oxygen - $6 \frac{600 \cdot 00}{3681 \cdot 38}$
Calculated per cent.

\begin{tabular}{rr}
72.11 & 71.92 \\
6.77 & 6.49 \\
4.82 & 4.75 \\
16.30 & 16.84 \\
\hline 100.00 & 100.00
\end{tabular}

On comparing these calculated and found numbers, they will be seen to agree, and on subtracting the weight of one atom of chloride of platinum and hydrochloric acid from the atomic weight of the platinum salt of bebeerine, we find 


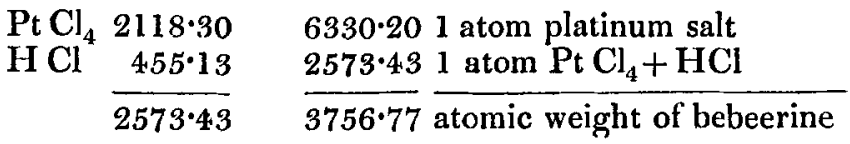

which is a close approximation to the found numbers. The rational formula for bebeerine then is

$$
\mathrm{C}_{35} \mathrm{H}_{40} \mathrm{~N}_{2} \mathrm{O}_{6} \text {. }
$$

It appears to have been sufficiently established by the experience of medical practitioners, that bebeerine possesses marked properties as a remedy for periodic diseases (Maclagan, Edinburgh Medical and Surgical Journal, April 184.5).

On comparing its composition with that of other vegetable alkalies possessed of similar remedial powers, such as quinine and cinchonine, it is not a little remarkable that it differs from them in atomic constitution, and that it is isomeric with morphia which acts as a pure narcotic. 'The atomic constitution of morphia, calculated from the formulæ deduced by Liebig and Regnault from their analyses, agrees perfectly with that given above for bebeerine. The composition of the two bases is, in fact, identical.

This is the first instance of isomerism occurring in substances belonging to the class of organic bases.

One very interesting conclusion regarding the action of medicinal substances appears to be deducible from these results, that similarity of physiological properties does not depend upon similarity in the proportions of their constituents. It seems probable that the mode in which their atoms are grouped has an important share in modifying their physiological actions; for in the present instance we have the same number of atoms both in morphia and bebeerine, but in the one producing a white crystalline body of narcotic qualities, in the other a yellow amorphous resinous-looking substance, acting as an anti-periodic. The difference in their physical properties in fact proves that their elements are differently arranged.

We have not been enabled to examine sipeerine, the substance left behind when pure bebeerine is dissolved out by means of æther. It occurs in very minute quantity, and requires a very tedious repetition of the treatment with æether to free it from the last traces of bebeerine. There seems, from some trials which we have made, good ground for believing that it is a distinct alkali, but it has not been obtained in sufficient quantity to enable it to be subjected to ultimate analysis. 